\title{
ENCUESTA A PRODUCTORES PARA ORIENTAR EL FITOMEJORAMIENTO DE FRIJOL EN ECUADOR ${ }^{1}$
}

\author{
Emmalea Garver Ernest ${ }^{2}$,Esteban Falconí-Castillo ${ }^{3}$,Eduardo Peralta-Idrovo ${ }^{3}$, James Kelly ${ }^{4}$
}

\begin{abstract}
RESUMEN
Encuesta a productores para orientar el fitomejoramiento de frijol en Ecuador. Se realizó una encuesta a más de cincuenta productores de frijol de los valles de Chota y Mira, ubicados al norte de Ecuador, en el año 2003, con la finalidad de recabar información y plantear objetivos para la implementación de un programa de mejoramiento participativo de frijol en Ecuador. Los productores fueron consultados acerca de las variedades de frijol que están cultivando actualmente, los métodos de producción empleados, los problemas de producción del cultivo y las características que deberían mejorarse en las nuevas variedades. Los principales problemas de producción reportados fueron los daños causados por mosca blanca (Trialeurodes vaporariorum), roya (Uromyces appendiculatus) y brúquidos (Acanthoscelides obtectus). Los agricultores han cambiado recientemente las clases comerciales de frijol que tradicionalmente cultivaban en respuesta a la demanda del mercado. En cuanto a las características que deberían poseer las nuevas variedades de frijol, indicaron alto rendimiento y semilla de tamaño grande con color y forma comercial. La costumbre de los agricultores de comprar semilla para cada siembra, y no de producir su propia semilla, fue identificada como un obstáculo potencial para el uso y mantenimiento de las nuevas variedades mejoradas de frijol en el área estudiada.
\end{abstract}

\begin{abstract}
A survey of bean farmers to guide breeding efforts in Ecuador. A survey of over fifty bean producers in the Mira and Chota river valleys in Northern Ecuador was conducted to gather the information required to set the objectives for a participatory plant breeding program to be implemented in the bush bean producing region of Ecuador. Farmers were asked to provide information about the bean varieties they currently grow, bean production practices, production problems, and suggestions of traits that should be improved in new bean varieties. Major production problems identified by the farmers were caused by whitefly (Trialeurodes vaporariorum), rust (Uromyces appendiculatus) and seed weevils (Acanthoscelides obtectus). Survey results indicated that farmers had recently switched the bean classes that they grew in response to changes in the market. High yield and seed characteristics related to marketability were identified as traits important for new bean varieties. Farmer's practice of purchasing seed for each planting, rather than saving their own seed, was identified as a potential obstacle to the introduction of improved varieties to increase yield and reduce production costs in the region studied.
\end{abstract}

Key words: Phaseolus vulgaris, participatory approaches, participatory plant breeding.

Palabras clave: Phaseolus vulgaris, enfoques participativas, fitomejoramiento participativo.

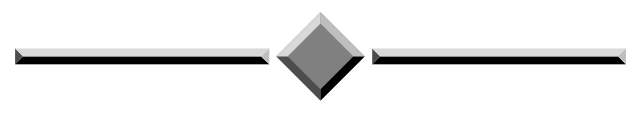

\footnotetext{
Recibido: 2 de mayo, 2007. Aceptado: 18 de enero, 2008.

2 University of Delaware, Carvel Research and Education Center, 16483 County Seat Hwy, Georgetown, DE 19947. Correo electrónico: emmalea@udel.edu

3 Instituto Nacional Autónomo de Investigaciones Agropecuarias (INIAP), Ecuador. Correo electrónico: estefalc@hotmail.com

4 Michigan State University, Department of Crop and Soil Sciences, East Lansing, MI 48824. Correo electrónico: kellyj@msu.edu
} 


\section{INTRODUCCIÓN}

El frijol común (Phaseolus vulgaris L.) es la leguminosa de mayor área de cultivo y consumo en Ecuador. El consumo de frijol en Ecuador se da en grano seco y grano con alto contenido de humedad, cosechada antes de la madurez fisiológica (de aquí en adelante referida como grano fresco). Los valles de los ríos Chota y Mira en las provincias norteñas de Imbabura y Carchi en Ecuador se encuentran entre las áreas productoras de frijol más importantes del país. De acuerdo con el Censo Agrícola del año 2001, las provincias de Imbabura y Carchi produjeron el $30 \%$ de grano seco y el $17 \%$ de grano fresco de la producción total de frijol del país (Ministerio de Agricultura y Ganadería del Ecuador 2002). Esfuerzos en investigación participativa junto a agricultores con el objetivo de mejorar los rendimientos de frijol en la región se iniciaron en el año 2002, por el Instituto Nacional Autónomo de Investigaciones Agropecuarias (INIAP) en colaboración con Michigan State University (MSU) y financiados por el Bean/Cowpea CRSP [http://www. isp.msu.edu/CRSP/].

El desarrollo y distribución de variedades de frijol mejoradas para el área fue una de las estrategias planteadas para mejorar los rendimientos del cultivo. Los investigadores y los agricultores cooperantes decidieron emplear metodologías de mejoramiento participativo de cultivos (MPC), el cual consiste en involucrar a los agricultores y a otros participantes en la evaluación y selección de variedades o líneas mejoradas. Los métodos de MPC pueden ser divididos en dos categorías generales: Selección participativa de variedades (SPV) y fitomejoramiento participativa. En el caso de SPV, los agricultores seleccionan las nuevas variedades a partir de líneas avanzadas genéticamente estables; mientras que, en fitomejoramiento participativo, los agricultores seleccionan a partir de poblaciones segregantes (Almekinders y Elings 2001). Los agricultores e investigadores involucrados en el proyecto reportaron que seguirán empleando SPV para desarrollar, seleccionar y entregar las nuevas variedades de frijol.

Técnicas de encuesta han sido utilizadas en MPC para solicitar a los agricultores sus opiniones de líneas o variedades en ensayos (Sthapit et al. 1996, Ceccarelli et al. 2001, Smith et al. 2001). De esta manera, los agricultores son involucrados en la selección de materiales para producción de semilla a gran escala o para avanzar en generaciones segregantes para eventuales selecciones. Por el contrario, la encuesta para productores de frijol de los valles de los ríos Chota y Mira, aquí descrita, fue diseñada y conducida para recolectar información de muchos agricultores de varias comunidades, grupos étnicos y niveles económicos acerca de sus prácticas actuales de producción de frijol, preferencias y problemas. Esta información fue recopilada para utilizarla en la definición de los objetivos del programa y orientar el mejoramiento de frijol desde el inicio del proceso. La participación de los agricultores en etapas iniciales del proceso de mejoramiento fue sugerida por Morris y Bellon (2004). Sin embargo, para el estudio descrito aquí, se pretende también involucrar a los agricultores en el subsiguiente proceso de mejoramiento, que incluye la evaluación de líneas y variedades.

\section{MATERIALES Y MÉTODOS}

El presente cuestionario fue diseñado para obtener información que será utilizada en el establecimiento de los objetivos de mejoramiento de frijol en Ecuador y para guiar el proceso de desarrollo y selección de variedades con productores de frijol de los valles del río Mira y Chota. Las comunidades seleccionadas, para realizar las encuestas, estuvieron localizadas dentro de las principales áreas de producción de frijol en los valles mencionados. Los agricultores entrevistados fueron aquellos que se encontraban trabajando en los campos de frijol o en labores de trilla durante la encuesta, para cumplir con el requisito de que debían haber cultivado frijol en aquel ciclo. Dos entrevistadores trabajaron durante cinco días dentro del mes de Mayo de 2003, totalizando 56 encuestas en diez diferentes comunidades de los dos valles. El $18 \%$ de entrevistados correspondieron a agricultoras mujeres. Las preguntas realizadas fueron las siguientes:

\section{Preguntas acerca de tenencia de tierra}

¿Qué superficie de tierra posee?

¿Cuánta superficie está cultivada?

Dibuje un mapa de la propiedad que cultiva. 
Para cada parcela de terreno, la siguiente información fue requerida a los agricultores:

¿Qué superficie tiene (la parcela)?

¿Cuál de estas cuatro líneas parece a la ladera de este lote? (Una ficha mostrando cuatro líneas de pendiente fue utilizada para esta pregunta).

¿Qué cultivos ha sembrado en este lote en los dos últimos años?

\section{Preguntas acerca de las variedades de frijol}

¿Qué variedades de frijol sembró el último año?

La siguiente información fue requerida a los agricultores para cada variedad de frijol:

¿Cuántos años ha cultivado usted esta variedad? dad?

¿Cuándo (en qué meses) sembró usted esta varie-

¿Cuánta semilla sembró (cada ciclo)?

¿Cómo consiguió la semilla de esta variedad que sembró el año pasado?

Si la semilla fue producida por él mismo, en un ciclo anterior, se preguntó lo siguiente: riedad?

¿Hace cuántos años compró semilla de esta va-

¿Qué hábito de crecimiento tiene esta variedad?

¿Cuál de estas semillas se parece más en tamaño? (Semillas de tres diferentes tamaños fueron mostradas a los agricultores).

¿Cuál es el color de la semilla de esa variedad?

¿Cómo se consume esta variedad? (¿En grano seco o fresco?)

¿Consumió la variedad el año pasado?
¿Vendió usted esta variedad el año pasado?

¿Cuánto vendió?

¿Qué precio recibió?

¿Dónde vendió?

¿Qué le gusta acerca de esta variedad?

¿Qué no le gusta acerca de esta variedad?

En el año pasado ¿Cultivó una mezcla de variedades de frijol en el mismo lote? Si respondió que sí, los agricultores fueron consultados en lo siguiente:

¿Qué variedades cultivó (en forma de mezcla)?

El año pasado ¿Cultivó frijol junto con otro cultivo? Si respondió que sí, se preguntó o siguiente:

¿Qué variedades de frijol cultivó en este modo?

\section{Preguntas acerca de problemas de producción}

¿Cuáles son los problemas de producción de frijol más importantes en su propiedad?

En los dos últimos años, ¿Usted vio a alguna plaga de frijol que se asemeje a una de estas fotos? Fotografías de $13 \times 20 \mathrm{~cm}$ con las siguientes plagas de frijol fueron mostradas a los agricultores: mosca blanca (Trialeurodes vaporariorum), minador de hoja (Liriomyza sp.), ácaro (Tetranychus sp.) y brúchido (Acanthoscelides obtectus).

Para cada plaga que el agricultor reportó haber observado en su lote se preguntó lo siguiente:

¿Cómo se llama esta plaga?

¿Usted controla esta plaga? Si respondió que sí, ¿Cómo la controla?

En su opinión, esta plaga: (1) Causa mucho daño a la cosecha de frijol, (2) Causa daño moderado a la cosecha de frijol, o (3) No daña la cosecha de frijol. 
En los dos últimos años, ¿Usted vio a alguna enfermedad de frijol que se asemeje a una de estas fotos? Fotografías de $13 \times 20 \mathrm{~cm}$ con plantas de frijol mostrando síntomas de enfermedades de frijol fueron mostradas a los agricultores. Los síntomas de enfermedades fueron los siguientes: antracnosis (Colletotrichum lindemuthianum), roya (Uromyces appendiculatus), bacteriosis común (Xanthomonas axonopodis pv. phaseoli), mancha angular (Phaseoisariopsis griseola), mildiú (Erysiphe polygoni) pudrición radicular (Rhizoctonia solani) y virus del mosaico común (BCMV).

Para cada enfermedad que el agricultor reportó haber observado en su lote de cultivo se preguntó lo siguiente:

¿Cómo se llama esta enfermedad?

¿Usted controla esta enfermedad? Si respondió que si, ¿Cómo la controla?

En su opinión, esta enfermedad: (1) Causa mucho daño a la cosecha de frijol, (2) Causa daño moderado a la cosecha de frijol, o (3) No daña la cosecha de frijol?

¿Conoce a una variedad de frijol que tenga resistencia a esta enfermedad? Si respondió que sí; ¿Cómo se llama esta variedad con resistencia?

\section{Preguntas acerca de las preferencias para las nue- vas variedades de frijol}

¿Cuáles son las características más importantes de una variedad de frijol?

¿Qué características quisiera que se mejore en las variedades que cultiva?

¿Cómo se entera de las nuevas variedades de frijol?

¿Adónde iría usted para obtener una nueva variedad de frijol?

Si siembra una variedad de frijol por primera vez, ¿Cuánta semilla quisiera sembrar?

\section{Preguntas demográficas}

¿Cuántos años tiene?

¿Qué nivel de educación posee?

¿Género? (por observación)

¿Cuántas personas componen su familia?

¿Con qué frecuencia consume frijol?

¿Diariamente? (¿Cuántas veces?) o ¿semanalmente? (¿Cuántas veces?).

¿Qué cantidad de frijol prepara para cada comida?

Los datos de la encuesta fueron analizados mediante el paquete estadístico SPSS (www.spss.com).

\section{RESULTADOS Y DISCUSIÓN}

\section{Caracterización demográfica y sistemas de produc- ción}

La mayoría de los agricultores productores de frijol entrevistados tenían más de 35 años (79\%) y solamente educación primaria (63\%). Los hogares estaban generalmente compuestos por cinco miembros o más. Casi todos los agricultores entrevistados (93\%) señalaron ser propietarios de las tierras que cultivaban a la fecha de la encuesta. La superficie de terreno, sin embargo, fue relativamente pequeña; $39 \%$ de los agricultores poseían una hectárea o menos y $64 \%$ poseían dos hectáreas o menos. Los agricultores de frijol en los valles de los ríos Mira y Chota han estado practicando agricultura de pequeña escala y de labor intensa, ya que la superficie de terreno es limitada y el número de integrantes del hogar es alto.

En lugar de cultivar muchos cultivos, los agricultores tienden a especializarse en unos pocos. La mayoría de los agricultores $(71 \%)$ reportaron cultivar solamente una o dos especies de cultivos además del frijol. Sin embargo, la diversidad de cultivos explotados en el área es grande, con veinte diferentes cultivos 
reportados. Esta diversidad reportada posiblemente se deba a los diferentes microclimas presentes en las cuencas de los ríos Chota y Mira. Caña de azúcar y yuca, por ejemplo, fueron cultivadas en las partes más bajas, mientras que cultivos como zanahoria blanca, zanahoria amarilla, guisante, y papa fueron cultivadas en las partes más altas del área. Además de frijol los cultivos más comunes fueron tomate (cultivado por $39 \%$ de los agricultores entrevistados), pimiento y maíz (cultivado por 20 y $30 \%$ de los agricultores entrevistados, respectivamente).

Casi todos los cultivos que los agricultores reportaron, fueron cultivos para la venta (e.g. tomate, caña de azúcar, pimiento, anís) y no para subsistencia. Pocos de los cultivos reportados podrían servir para venta y autoconsumo (e.g. frijol, maíz, yuca, papa, y camote) y exclusivamente para autoconsumo el gandul (Cajanus cajan). Al parecer, los agricultores utilizan su limitada superficie de terreno cultivable para producir pocos cultivos de intensa labor para la venta. El hecho de que estos agricultores son de pequeña escala de frutales, hortalizas y gramíneas significa que los precios y los mercados de los cultivos que producen tienen un substancial impacto en sus hogares. Los frijoles son únicos en este tipo de sistema de producción, ya que tienen un buen precio en el mercado y además significan una buena fuente nutricional para los agricultores y sus familias, aún si los precios bajasen al punto de ser un cultivo no rentable. Algunos de los otros cultivos que los agricultores producen como tomate, pimiento, caña de azúcar y cebolla no poseen este potencial.

Los datos recolectados de consumo de frijol en esta encuesta indicaron que los agricultores productores de frijol, en los valles de los ríos Chota y Mira, consumen en promedio cinco veces por semana un plato que contenga frijoles y anualmente un total de $38,1 \pm 6,68 \mathrm{~kg}$ por persona por año. El hecho de que el frijol sea una parte tan importante en la dieta de los productores en esta área, fortalece el valor de esta leguminosa, ya sea un cultivo de subsistencia o para la venta.

\section{Variedades de frijol utilizadas para el cultivo por los agricultores}

Los agricultores entrevistados mencionaron que cultivan 12 clases comerciales de frijol. La clasificación está determinada por la apariencia y tamaño de la semilla (Cuadro 1). Dentro de una clase comercial en particular existen algunas variedades y las plantas de frijol pueden variar en el hábito de crecimiento, resistencia a enfermedades, tolerancia a estreses y en el rendimiento potencial. A pesar de esta diversidad, el $84 \%$ de los agricultores cultivaron solamente una o dos clases comerciales diferentes de frijol durante el ciclo. El número máximo de clases cultivadas reportadas por los agricultores fue de cuatro.

Nueve de las 12 clases comerciales de frijol cultivado en este ciclo fueron igualmente destinadas para la venta y autoconsumo (Cuadro 1). Las tipo Negro y Panamito son utilizadas exclusivamente para cosecha en grano seco, mientras que las tipo Blanco de Leche y Vaquita son exclusivamente para cosecha en grano fresco. Las clases restantes son consumidas o vendidas en cualquiera de los dos estados (seco o fresco).

Encuestas anteriores realizadas a agricultores en los valles de los ríos Chota y Mira revelaron que, con excepción de algunos pequeños productores quienes cultivaron la clase comercial Panamito, los agricultores produjeron frijol de las clases comerciales Calima Negro y Calima Rojo para la exportación a Colombia (Peralta et al. 2001). En la presente encuesta, sin embargo, los agricultores reportaron que las clases comerciales más frecuentemente cultivadas corresponden a las clases Rojo Injerto y Negro. Los datos presentados en el Cuadro 2 muestran que Calima Rojo tiene una tasa baja de adopción (adoptada en los pasados dos años) comparado con otras importantes clases. La mayoría de agricultores que cultivan Calima Rojo lo han cultivado por más de seis años.

En comparación, un alto porcentaje de agricultores están cultivando las clases Negro, Panamito, Matahambre, Canario y Bayo o Crema que han sido adoptadas recientemente. A pesar de que estas clases han sido históricamente cultivadas en el área, los agricultores no han tenido opción o facilidades para la comercialización de semilla. Los comentarios de los agricultores y los resultados de las encuestas sugieren que, desde que las exportaciones a Colombia disminuyeron o cesaron, algunos agricultores abandonaron las variedades de clase comercial de Calima Rojo por las clases de frijol que tienen demanda en el mercado local. Las clases como Rojo Injerto, Blanco de Leche 
Cuadro 1. Clases comerciales de frijol cultivadas por los agricultores entrevistados en los valles de Chota y Mira, descripción, \% de utilización y usos. Ecuador, 2003.

\begin{tabular}{|c|c|c|c|c|c|c|c|}
\hline $\begin{array}{c}\text { Clase } \\
\text { comercial }\end{array}$ & Color & Tamaño/forma & $\begin{array}{l}\text { \% pro- } \\
\text { ductores }\end{array}$ & $\begin{array}{l}\text { Kilos. sem- } \\
\text { brado }\end{array}$ & $\begin{array}{l}\text { Para auto- } \\
\text { consumo o } \\
\text { venta }\end{array}$ & $\begin{array}{c}\text { Madurez } \\
\text { para venta }\end{array}$ & $\begin{array}{c}\text { Madurez } \\
\text { para } \\
\text { consumo }\end{array}$ \\
\hline $\begin{array}{l}\text { Rojo } \\
\text { injerto }\end{array}$ & rojo/rosa/blanco & med./ovalada & 45 & 2693 & $\begin{array}{l}\text { autoconsumo/ } \\
\text { venta }\end{array}$ & $\mathrm{seco} /$ fresco & seco/fresco \\
\hline Negro & negro & pequeño/ovalada & 29 & 788 & $\begin{array}{l}\text { autoconsumo/ } \\
\text { venta }\end{array}$ & seco & $\begin{array}{l}\text { mayoría } \\
\text { seco }\end{array}$ \\
\hline $\begin{array}{l}\text { Blanco de } \\
\text { leche }\end{array}$ & blanco & grande/ariñonada & 21 & 653 & $\begin{array}{l}\text { autoconsumo/ } \\
\text { venta }\end{array}$ & mayoría fresco & $\begin{array}{l}\text { mayoría } \\
\text { fresco }\end{array}$ \\
\hline Calima negro & $\begin{array}{c}\text { morado/rojo/ } \\
\text { blanco }\end{array}$ & grande/ariñonada & 20 & 890 & $\begin{array}{l}\text { autoconsumo/ } \\
\text { venta }\end{array}$ & mayoría seco & seco/fresco \\
\hline Calima rojo & rojo/rosa/blanco & grande/ariñonada & 18 & 803 & $\begin{array}{l}\text { autoconsumo/ } \\
\text { venta }\end{array}$ & mayoría seco & seco/fresco \\
\hline Panamito & blanco & pequeño/ovalada & 11 & 207 & $\begin{array}{l}\text { autoconsumo/ } \\
\text { venta }\end{array}$ & seco & seco \\
\hline Canario & amarillo & med./redonda & 7 & 765 & $\begin{array}{l}\text { autoconsumo/ } \\
\text { venta }\end{array}$ & seco & seco/fresco \\
\hline Matahambre & amarillo & med./ovalada & 5 & 140 & $\begin{array}{l}\text { autoconsumo/ } \\
\text { venta }\end{array}$ & -- & seco/fresco \\
\hline Bayo blanco & crema & med./redonda & 4 & 113 & venta & seco/fresco & seco/fresco \\
\hline Vaquita & rosa/blanco & med./ovalada & 2 & 90 & venta & fresco & fresco \\
\hline Rojo & rojo & med./redonda & 2 & 11 & $\begin{array}{l}\text { autoconsumo/ } \\
\text { venta }\end{array}$ & seco/fresco & seco/fresco \\
\hline Musgo & café & pequeño/ovalada & 2 & 11 & autoconsumo & -- & $\operatorname{seco}$ \\
\hline
\end{tabular}

y Calima Negro, las cuales han sido cultivadas tradicionalmente para la venta, continúan siendo cultivadas en la actualidad porque también tienen demanda en el mercado local. Finalmente, la tendencia de cultivar algunas de las clases menos explotadas destinadas para venta, mencionadas anteriormente, no sólo fue de pequeños agricultores. A pesar de que los agricultores entrevistados fueron pequeños productores principalmente, el productor entrevistado con la superficie de terreno más grande para cultivo de frijol (10 ha) estuvo cultivando las clases Canario, Bayo, Matahambre y Rojo Injerto.

La clase Blanco de Leche es única en términos de cómo se comercializa. Ésta es comercializada en grano fresco en Semana Santa antes de Pascua y es parte de uno de los platos tradicionales (Fanesca) para esta celebración. De acuerdo a los entrevistados, en el periodo previo a la encuesta, los agricultores comercializaron esta clase a un precio de hasta US $\$ 20.00$ por bulto (un bulto es técnicamente una medida de volumen, sin embargo, un bulto de frijol en grano fresco alcanza un peso entre $40-45 \mathrm{~kg}$ que incluye semilla y valvas). Esta clase alcanza el precio más alto entre los frijoles comercializados en estado de grano fresco (Cuadro 3). Sin embargo, los agricultores plantaron un área comparativamente más pequeña de esta clase que otras. Algunos agricultores señalaron que las variedades de estas clases son muy susceptibles a las enfermedades y también que el precio baja sustancialmente después de Semana Santa. En este sentido, cultivar las variedades de la clase comercial Blanco de Leche puede ser una inversión riesgosa debido a las fluctuaciones en el precio y la susceptibilidad a las enfermedades. 
Cuadro 2. Años de explotación de las clases comerciales de frijol que han sido cultivadas en los valles de los ríos Chota y Mira agrupadas por porcentaje de agricultores que reportaron haberlas cultivado. Ecuador, 2003.

\begin{tabular}{lcccc}
\hline \multirow{2}{*}{ Clase comercial } & \multicolumn{3}{c}{ \% de agricultores que han cultivado la clase por el número de años especificado } \\
\cline { 2 - 5 } & $\mathbf{1 - 2}$ años & $\mathbf{3 - 5}$ años & $\mathbf{6 - 1 0}$ años & >10 años \\
\hline Rojo injerto & 24 & 24 & 40 & 12 \\
Negro & 56 & 13 & 13 & 19 \\
Blanco de leche & 17 & 17 & 17 & 50 \\
Calima negro & 45 & 9 & 36 & 9 \\
Calima rojo & 10 & 10 & 50 & 30 \\
Panamito & 50 & 0 & 0 & 50 \\
Canario & 75 & 0 & 0 & 25 \\
Matahambre & 33 & 0 & 0 & 67 \\
Bayo blanco & 100 & 0 & 0 & 0 \\
Vaquita & 100 & 0 & 0 & 0 \\
Rojo & 0 & 0 & 0 & 100 \\
Musgo & 0 & 0 & 0 & 100 \\
\hline
\end{tabular}

Cuadro 3. Precios promedio de las clases comerciales de frijol cultivadas en los valles de los ríos Chota y Mira reportados por los agricultores en US\$/quintal o US\$/bulto. Ecuador, 2003.

\begin{tabular}{lc}
\hline Clase comercial & $\begin{array}{c}\text { Precio promedio en dólares } \\
\text { americanos }\end{array}$ \\
\hline Grano seco & $\mathbf{4 5}$ kg (100 libras) \\
Rojo injerto & 30 \\
Negro & 28 \\
Calima negro & 32 \\
Calima rojo & 31 \\
Panamito & 26 \\
Matahambre & 25 \\
& \\
Grano fresco & bulto \\
Rojo injerto & 14 \\
Blanco de leche & 16 \\
Vaquita & 15 \\
Rojo & 10 \\
\hline
\end{tabular}

${ }^{1}$ Frijol para grano fresco se vende en vaina. Un bulto es técnicamente una medida de volumen, sin embargo, un bulto de frijol en grano fresco alcanza un peso entre $40-45 \mathrm{~kg}$.

\section{Fuentes de semilla de los agricultores}

El 36\% de los agricultores entrevistados mencionaron que siembran su propia semilla, la cual proviene normalmente del ciclo anterior. La semilla de frijol que no fue guardada proviene de diversas fuentes. La mayoría fue comprada en los mercados, dentro o fuera de la comunidad a la cual pertenece el agricultor (Cuadro 4). (Existe muy poca diferencia o no existe ninguna entre la semilla comercializada para la siembra y la empleada para el consumo). Un reducido número de agricultores señaló que la semilla utilizada en el ciclo de cultivo previo a la encuesta fue obtenida de un vecino por intercambio de semilla, ONG, cooperativa o del propietario del lote de terreno en el caso de quienes alquilaron o sembraron al partir (situación en la que el agricultor participa en sociedad con el propietario del lote, donde el agricultor realiza todas las labores agrícolas culturales y el propietario del terreno contribuye con la tierra, agua y los insumos agrícolas y la cosecha se distribuye en partes iguales). De todos los agricultores entrevistados el $91 \%$ ha obtenido semilla de alguna fuente fuera de sus lotes de producción en los pasados tres años.

Las fuentes de semilla también difieren de acuerdo a las clases comerciales. Un alto porcentaje de 
Cuadro 4. Origen de la semilla de frijol de las doce clases comerciales expresado como porcentaje de agricultores que cultivaron cada clase. Ecuador, 2003.

\begin{tabular}{|c|c|c|c|c|c|c|c|}
\hline $\begin{array}{c}\text { Clase } \\
\text { comercial }\end{array}$ & $\begin{array}{c}\% \text { Semilla } \\
\text { propia }\end{array}$ & $\begin{array}{c}\% \text { Semilla de } \\
\text { otra fuete }\end{array}$ & $\begin{array}{c}\% \text { Semilla } \\
\text { comprada den- } \\
\text { tro de la comu- } \\
\text { nidad } \\
\end{array}$ & $\begin{array}{c}\% \text { Semilla } \\
\text { comprada en } \\
\text { otra comuni- } \\
\text { dad }\end{array}$ & $\begin{array}{c}\% \text { Semilla } \\
\text { obtenida por } \\
\text { intercambio }\end{array}$ & $\begin{array}{c}\% \text { Semilla } \\
\text { obtenida del } \\
\text { dueño }\end{array}$ & $\begin{array}{c}\% \text { Semilla } \\
\text { obtenida de } \\
\text { cooperativa o } \\
\text { ONG }\end{array}$ \\
\hline $\begin{array}{l}\text { Rojo } \\
\text { injerto }\end{array}$ & 16 & 84 & 20 & 52 & 4 & 8 & 0 \\
\hline Negro & 13 & 88 & 6 & 50 & 0 & 0 & 31 \\
\hline $\begin{array}{l}\text { Blanco de } \\
\text { Leche }\end{array}$ & 75 & 25 & 0 & 17 & 8 & 0 & 0 \\
\hline Calima Negro & 36 & 64 & 18 & 36 & 9 & 0 & 0 \\
\hline Calima Rojo & 60 & 40 & 0 & 30 & 10 & 0 & 0 \\
\hline Panamito & 33 & 67 & 17 & 17 & 0 & 0 & 33 \\
\hline Canario & 0 & 100 & 25 & 0 & 0 & 25 & 50 \\
\hline Matahambre & 0 & 100 & 0 & 67 & 33 & 0 & 0 \\
\hline Bayo Blanco & 0 & 100 & 0 & 0 & 0 & 0 & 100 \\
\hline Vaquita & 0 & 100 & 0 & 100 & 0 & 0 & 0 \\
\hline Rojo & 100 & 0 & 0 & 0 & 0 & 0 & 0 \\
\hline Musgo & 100 & 0 & 0 & 0 & 0 & 0 & 0 \\
\hline
\end{tabular}

agricultores utilizaron su propia semilla de Blanco de Leche $(75 \%)$ y Calima Rojo $(60 \%)$, comparado con otras clases comerciales comúnmente cultivadas: Rojo Injerto (16\%), Negro (13\%), Calima Negro (36\%) y Panamito (33\%). Los agricultores que cultivaron Blanco de Leche comentaron que la semilla de esta clase tiene un precio más alto comparado con el resto de clases comerciales de frijol. El costo de la semilla de Blanco de Leche sería más alto ya que es únicamente comercializado para la venta en grano fresco y la semilla madura y seca no está disponible regularmente en los mercados.

\section{Problemas de producción de frijol}

Los problemas de producción mayormente señalados fueron: mosca blanca $(96 \%)$, roya $(86 \%)$ y brúquidos $(75 \%)$. Estos problemas de producción también fueron considerados como los más importantes para alcanzar un rendimiento aceptable en el cultivo de frijol (Figura 1). Algunos agricultores identificaron ácaros, minador de hoja, pudrición radicular, antracnosis, mildiú, y bacterosis común como problemas de producción de frijol. Pocos agricultores mencionaron mancha angular o virus del mosaico común. La mayoría de agricultores, que destacaron problemas en sus lotes de cultivo, señalaron haber empleado alguna clase de plaguicida como una medida de control, particularmente en el caso de mosca blanca (94\%), brúquidos $(76 \%)$ y roya $(98 \%)$. El uso de plaguicidas entre los agricultores fue casi total, ya que el $98 \%$ de los entrevistados mencionaron haber aplicado, por lo menos una vez, plaguicidas en su cultivo de frijol.

\section{Preferencias y recomendaciones de los agricultores para el mejoramiento de variedades}

De acuerdo a los agricultores, el alto rendimiento y resistencia a enfermedades, son las características más importantes para ser incorporadas en las nuevas variedades. Cincuenta y cuatro por ciento de los agricultores mencionaron que el rendimiento es una de las características que debería ser mejorada en las variedades que actualmente están siendo cultivadas, y el 36\% de los entrevistados señalaron que la característica a mejorar debería ser resistencia a las enfermedades 


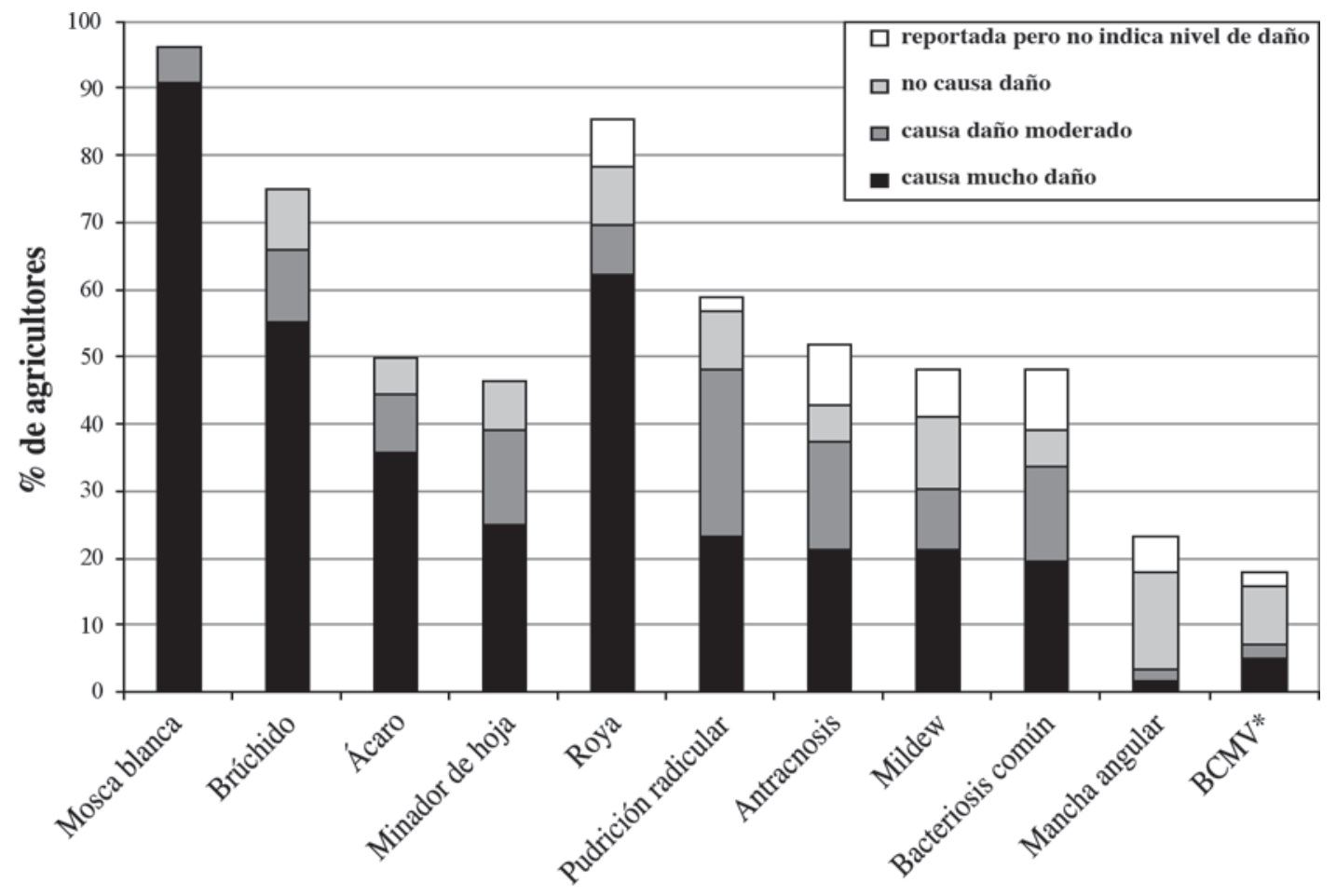

Figura 1. Incidencia y severidad de plagas y enfermedades de frijol en los valles de Mira y Chota en el norte de Ecuador expresado como porcentaje de agricultores entrevistados. Ecuador, 2003.

*BCMV es virus del mosaico común.

(Cuadro 5). Sin embargo, en respuesta a la pregunta "¿Conoce usted una variedad de frijol que tenga resistencia a esta enfermedad?", un número significativo respondió que no creen que sea posible que existan variedades que sean resistentes a ciertas enfermedades. Si líneas o variedades de frijol fuesen introducidas al área, ensayos demostrativos entre variedades en uso y las nuevas variedades mejoradas serían necesarios para demostrar a los agricultores la existencia y valor de las variedades con resistencia a enfermedades.

Un total de $61 \%$ de agricultores mencionaron que las características relacionadas con la calidad de semilla son cualidades importantes, sin embargo solamente el 16\% mencionó como una característica a mejorar en un programa de mejoramiento genético. Esto sugiere que la mayoría de agricultores piensan que la calidad de la semilla de frijol no es una característica que deba ser mejorada en las variedades que actualmente poseen los agricultores. Consecuentemente, las nuevas variedades deben tener una calidad de semilla similar o superior a las que se encuentran en posesión de los agricultores.

\section{CONCLUSIONES}

\section{Clases de frijol seleccionadas para el cultivo por los agricultores entrevistados}

La encuesta reveló que los agricultores de los valles de los ríos de Mira y Chota, que tradicionalmente han cultivado las variedades de la clase comercial 
Cuadro 5. Características deseadas para las nuevas variedades de frijol señaladas por los agricultores de los valles de los ríos Mira y Chota en el norte del Ecuador. 2003.

\begin{tabular}{rcc}
\hline \multicolumn{1}{r}{ Características } & $\begin{array}{c}\text { Citado para mejorar en las variedades } \\
\text { actuales }\end{array}$ & $\begin{array}{c}\text { Identificado como una importante característi- } \\
\text { ca en una variedad de frijol }\end{array}$ \\
\hline Específica & \% de agricultores & \% de agricultores \\
Características de rendimiento & $\mathbf{5 3 , 6}$ & $\mathbf{4 4 , 6}$ \\
alto rendimiento & 53,6 & 42,9 \\
vainas largas & 1,8 & 1,8 \\
Características de semilla & $\mathbf{1 6 , 1}$ & $\mathbf{6 0 , 7}$ \\
semilla pesada & 7,1 & 41,1 \\
color de semilla & 0,0 & 26,8 \\
brillo de semilla & 1,8 & 12,5 \\
calidad de semilla & 7,1 & 0,0 \\
Características de la planta & $\mathbf{4 2 , 9}$ & $\mathbf{5 1 , 8}$ \\
resistente a enfermedades/sano & 35,7 & 19,6 \\
planta alta & 3,6 & 12,5 \\
vigoroso/follaje abundante & 0,0 & 26,8 \\
alta floración & 3,6 & 3,6 \\
adaptación local & 1,8 & 3,6 \\
resistente a sequía & 1,8 & 0,0 \\
Sabor & $\mathbf{1 4 , 3}$ & $\mathbf{1 4 , 3}$ \\
Aceptado por el mercado & 12,5 & 12,5
\end{tabular}

Calima Rojo para la exportación a Colombia, han respondido a la pérdida del mercado colombiano con el cambio a otras clases de frijol que pueden ser comercializadas a nivel doméstico. Los datos de esta encuesta indicaron que las clases comerciales Rojo Injerto y Negro son las más cultivadas en el área. La tasa de adopción reciente fueron también alta para las clases Calima Negro, Panamito, Canario y Bayo. En el momento de la encuesta, los esfuerzos de mejoramiento en proceso estuvieron enfocados en las clases Calima Rojo, Rojo Injerto y Canario. Por los resultados de la encuesta, también se debería poner interés al mejoramiento de las clases comerciales Negro y Panamito, las cuales fueron consideradas de menor importancia anteriormente. En este caso, el conocimiento popular y, más aún, el resultado de encuestas recientes (Peralta et al. 2001) no presentan un cuadro preciso y adecuado de las clases comerciales de frijol que los agricultores estuvieron cultivando para el mercado.

\section{Comercialización}

La encuesta también reveló que la mayoría de agricultores de los valles de los ríos Chota y Mira no son agricultores de subsistencia, sino son productores de pocos cultivos de labor intensiva para la venta en pequeña escala. Como resultado, la comercialización del frijol que ellos producen es importante en sus ingresos económicos. El cambio de la clase comercial Calima Rojo por otras clases de frijol fue causado por su inviabilidad para exportar las variedades de esta clase a Colombia como ocurría en el pasado. Los agricultores también mencionaron frecuentemente acerca de la baja calidad de la semilla que ellos producen, la cual afecta a la comercialización, así la variedad de frijol sea buena. Unos agricultores mencionaron que la comercialización es un aspecto importante y muchos de ellos bromearon expresando que, la característica que desean que se mejore en las nuevas variedades 
es "el precio". Debido a que la comercialización es sumamente importante para los productores de frijol en el área, es una cuestión crítica que los mejoradores enfoquen los esfuerzos en las clases comerciales, manteniendo las características de las semillas de las variedades locales que son preferidas por los comerciantes y consumidores. En el futuro, sería muy ventajoso consultar con los intermediarios en el mercado de frijol y los comerciantes finales para confirmar que las nuevas variedades que están siendo desarrolladas mantienen la calidad de semilla de las variedades tradicionales.

\section{Producción de semilla propia}

Los agricultores entrevistados tendieron a no usar su propia semilla y por el contrario, la mayoría, la compraron. Esta práctica es de alguna manera incompatible con las metodologías de fitomejoramiento participativo que los investigadores del INIAP y de MSU planificaron emplear en el área, ya que los agricultores no mantendrían la semilla de las nuevas variedades en su poder en largo plazo. De hecho, el sistema de semillas actual, en el que los agricultores siembran variedades de frijol que no han sido producidas para ser "semilla de calidad", no es compatible con la liberación de una variedad mejorada que se asemeja a la variedad local. Una posible solución a esta limitante podría ser el trabajar en asociación con comerciantes y cooperativas de producción agrícola que operan en el área para cambiar el sistema de comercialización de semilla vigente. Por lo menos, una cooperativa que opera en el área vendió semilla a los agricultores para después comprar la producción. Una nueva variedad podría ser introducida en este sistema para mantener su calidad. En vista de que este inconveniente fue detectado en etapas de planificación del trabajo de mejoramiento, existe suficiente tiempo para desarrollar un plan antes de liberar las nuevas variedades.

\section{Problemas de producción}

Los datos de la encuesta revelaron que los principales problemas de producción en los valles de los ríos Chota y Mira son los daños que causan los ataques de mosca blanca, la infección causada por roya y el daño de la semilla almacenada causada por brúchidos.
Consecuentemente, los agricultores recurren a plaguicidas para controlar estos tres problemas. Mosca blanca podría ser controlada principalmente con el uso de químicos y mediante prácticas culturales. Sin embargo, el daño causado por el ataque de brúquidos y roya podría ser controlado mediante mejora genética. Siete clases de alelos diferentes que codifican para la producción de arcelina para el control del brúchido mexicano (Zabrotes subfasciatus) han sido caracterizados (Sales et al. 2000). En Ecuador, la especie de brúchido reportada como plaga de frijol pertenece a la especie Acanthoscelides obtectus por lo que los genes Arc no son tan efectivos. Sin embargo, el control de A. obtectus ha sido conseguido mediante una combinación de variedades de frijol enriquecidas en arcelina y el parasitoide $D i$ narmus basilis (Schmale et al. 2003). Adicionalmente, cuatro genes diferentes $A r c$ han sido empleados para el desarrollo de "stocks" genéticos con baja a moderada resistencia a A. obtectus en genotipos de frijol de clase comercial Negro y Panamito (Osborn et al. 2003). Estos genotipos podrían ser útiles al Programa de Mejoramiento de Frijol para Valles de los ríos Chota y Mira. La resistencia a roya en frijol está bien caracterizada y trabajos de incorporación de resistencia genética está en proceso en algunas de las clases comerciales importantes (Murillo et al. 1999). El mejoramiento para antracnosis de frijol (Colletotrichum lindemuthianum) ha sido también considerada cuando esta encuesta fue realizada $y$, de acuerdo a ella, la antracnosis no es una enfermedad importante en la cuenca baja de los ríos Chota y Mira. La incidencia de pudriciones radiculares reportadas por los agricultores en la encuesta fue de alguna manera poco entendida. Más investigación al respecto es necesaria para determinar los patógenos y plagas que están causando los problemas de raíz en el área.

La metodología empleada en la encuesta para determinar los principales problemas de producción de frijol en el área fue útil. Pedir a los agricultores que clasifiquen a los problemas de acuerdo al daño que causan al rendimiento fue también importante, ya que algunas plagas y enfermedades reportadas por los agricultores fueron consideradas como dañinas en menor grado que otras.

La encuesta a productores de frijol en los valles de los ríos Chota y Mira fue útil para orientar las actividades de mejoramiento de frijol que están y estarán siendo ejecutadas por INIAP y MSU para: (1) determinar 
qué clases comerciales de frijol deberían ser de mayor prioridad, (2) el entendimiento de que las características de calidad de la semilla son importantes para la comercialización; por ello, estas características deberán ser mantenidas en cualquier nueva variedad, (3) la confirmación de que los agricultores mayormente compran semilla en lugar de producir su propia semilla, debe ser tomado en consideración para cuando se planee liberar una nueva variedad en el área, (4) la identificación de los problemas de producción de frijol más importante en el área para dirigir el mejoramiento hacia ellos.

\section{LITERATURA CITADA}

Almekinders, CJM; Elings A. 2001. Collaboration of farmers and breeders: Participatory crop improvement in perspective. Euphytica 122: 425-238.

Ceccarelli, S; Grando, S; Bailey, E; Amri, A; El-Gelah, M; Nassif, F; Rezgui, S; Yahyaoui, A. 2001. Farmer participation in barley breeding in Syria, Morocco and Tunisia. Euphytica 122: 521-536.

Ministerio de Agricultura y Ganadería del Ecuador. 2002. Ecuador: Superficie mensual cosechada de frijol seco 2001. y Ecuador: Superficie mensual cosechada de frijol verde 2001. (en línea). Quito, Ecuador. Consultado 5 mayo 2006. Disponible en: http://www.sica. gov.ec/cadenas/frejol/docs/fseco11.htm. y http://www. sica.gov.ec/cadenas/frejol/docs/ftierno11.htm.

Morris, ML; Bellon, MR. 2004. Participatory plant breeding research: Opportunities and challenges for the international crop improvement system. Euphytica 136: 21-35.
Murillo, A; Pinzón, J; Peralta, E. 1999. Resistencia cuantitativa a roya en frijol arbustivo. In: D. L. Danial. ed. tercer taller de PREDUZA en resistencia duradera en cultivos altos en la zona andina. 27-29 sep. 1999, Cochabamba, Bolivia. p. 82-85.

Osborn, TC; Hartweck, LM; Harmsen, RH; Vogelzang, RD; Kmiecik, KA.; Bliss, FA. 2003. Registration of Phaseolus vulgaris genetic stocks with altered seed protein compositions. Crop. Sci. 43: 1570-1571.

Peralta, E; Guala, M; Tacán, M. 2001. Estudio de la producción, poscosecha, mercadeo y consumo de frijol arbustivo en el Valle del Chota, Ecuador. Programa Nacional de Leguminosas y Granos Andinos. Instituto Nacional Autónomo de Investigaciones Agropecuarias INIAP. Project Report, Quito, Ecuador. 25 p.

Sales, MP; Gerhardt, IR; Grossi-de-Sá, MF; Xavier-Filho, J. 2000. Do legume storage proteins play a role in defending seeds against bruchids? Plant Phys. 124: 515-522.

Schmale, I; Wäckers, FL; Cardona, C; Dorn, S. 2003. Combining parasitoids and plant resistance for the control of the bruchid Acanthoscelides obtectus in stored beans. J. Stored Products Research 39: 401-411.

Smith, ME; Castillo, F; Gómez, F. 2001. Participatory plant breeding with maize in Mexico and Honduras. Euphytica 122: 551-565.

Sthapit, BR; Joshi, KD; Witcombe, JR. 1996. Farmer participatory crop improvement. III. Participatory plant breeding, a case study for rice in Nepal. Exp. Agric. 32: 479-496. 